\title{
Perancangan Sistem Inventory Unit Logistik Bank Indonesia Bandung
}

\author{
Iwan Rijayana', Agnesia Tresti ${ }^{2}$, \\ ${ }^{1,2)}$ Program Studi Sistem Informasi, Fakultas Teknik, Universitas Widyatama \\ Jl. Cikutra No. 204 A, Bandung \\ Email: iwan.rijayana@widyatama.ac.id, agnesia.tresti@rocketmail.com
}

\begin{abstract}
In the era of information technology such as this present time efficiency and specialized as well as easy in getting any information it required institutions such as bank, always hold the inventory. In the absence of an inventory of institutions or companies at a time unable to meet its operational needs or activities.

Design and implementation of planning system in logistics unit inventory Bank Indonesia Bandung, is on such research produces a system application created using Vb.net and mean to solve a problem in the logistics unit of Bank Indonesia.

As for the problem solving can assist the logistics unit to simplify Bank Indonesia Bandung logistics unit as unit of inventory suppliers to transact the expenditure items. Logging request items using a computerized system to make it more easily and stored into the database so that very small accurence of data loss.

The result of this research are generating an application inventory system that serves to make a transaction request goods logistics unit as a provider goods supplies.
\end{abstract}

Keyword : Application, Bank Indonesia, Inventory, Logistic, System.

\begin{abstract}
Abstrak
Pada era teknologi informasi seperti sekarang ini, efisiensi waktu dan tenaga, serta kemudahan dalam mendapatkan suatu informasi sangatlah dibutuhkan. Disebuah instansi seperti bank, selalu mengadakan persediaan. Tanpa adanya persediaan, sebuah instansi ataupun perusahaan pada suatu waktu tidak dapat memenuhi kegiatan atau kebutuhan operasionalnya.

Desain dan implementasi dari perancangan Sistem Inventori di Unit Logistik Bank Indonesia Bandung, menghasilkan sebuah aplikasi sistem yang dibuat dengan menggunakan Vb.net untuk memecahkan masalah yang berada di Unit Logistik BI Bandung.

Adapun pemecahan masalah tersebut yaitu dapat membantu pihak Unit Logistik BI Bandung agar dapat mempermudah pihak unit logistik sebagai unit penyedia barang persediaan untuk melakukan transaksi pengeluaran barang. Pencatatan permintaan barang dengan menggunakan sistem terkomputerisasi agar lebih mudah dan tersimpan kedalam database sehingga sangat kecil terjadinya kehilangan data.

Hasil dari penelitian ini yaitu menghasilkan sebuah aplikasi sistem inventori yang berfungsi untuk melakukan transaksi permintaan barang kepada unit logistik sebagai penyedia barang persediaan.

Kata kunci : Sistem Informasi, Inventori, Logistik
\end{abstract}

Kata kunci: Aplikasi, Bank Indonesia, Inventori, Logistik, Sistem.

\section{Pendahuluan}

\subsection{Latar Belakang Masalah}

Sistem aplikasi dalam suatu instansi atau perusahaan sangatlah berperan baik untuk skala besar maupun kecil. Salah satu contoh dari sistem aplikasi tersebut adalah sistem aplikasi inventori. Dengan adanya sistem diharapkan dapat membantu insatansi atau perusahaan tersebut untuk menunjang kegiatan operasionalnya. Di sebuah instansi atau lembaga misalnya, terdapat sejumlah unit kerja. Salah satu unit kerja yang ada di Bank Indonesia Bandung adalah Unit Logistik. Di unit ini diperlukan suatu sistem aplikasi untuk mengolah data yang berkaitan dengan ruang lingkup logistik, seperti data barang, data supplier maupun data-data lainnya yang berkaitan dengan inventarisasi.

Unit Logistik yang ada di Bank Indonesia Bandung ini merupakan suatu unit yang salah satunya berperan dalam melaksanakan perencanaan, pelaksanaan, monitoring, dan evaluasi terhadap realisasi program kerja dan anggaran $\mathrm{KBI}$. Untuk mengolah atau mengelola data-datanya maka diperlukan suatu sistem aplikasi pengelolaan inventori di Unit Logistik yang baik agar manajemen data lebih optimal.

\subsection{Rumusan Masalah}

Salah satu unit kegiatan kerja yang ada di KBI ( Kantor Bank Indonesia ) Bandung adalah Unit Logistik. Kegiatan di Unit ini beragam, salah satu tugas 
pokoknya adalah sebagai penyedia barang maupun jasa untuk menunjang kegiatan operasional di KBI Bandung.

Unit logistik yang ada di Bank Indonesia Bandung ini merupakan suatu unit yang bertugas menatausahakan dan melaksanakan pengadaan barang dan jasa. Sejauh ini efektivitas kerja dalam pengolahan data logistik, khususnya aktivitas permintaan atau pengajuan barang persediaan, masih belum optimal, karena masih menggunakan cara manual, belum menggunakan sistem terkomputerisasi. Diharapkan dengan adanya sistem aplikasi Inventori ini dapat lebih memaksimalkan kinerja di Unit Logistik ini.

\subsection{Tujuan \& Manfaat Penelitian}

Maksud dan tujuan dari penelitian ini adalah untuk membangun aplikasi atau sistem aplikasi inventori yang ada di Unit Logistik Bank Indonesia Bandung.

Adapun tujuan dari pembangunan aplikasi ini diantaranya :

a. Membantu dalam aktivitas permintaan atau pengajuan barang persediaan di unit kerja Bank Indonesia Bandung ke Unit Logistik.

b. Membantu dalam aktivitas pengeluaran barang persediaan di Unit Logistik Bank Indonesia Bandung.

c. Mempermudah dan mempercepat dalam pencarian data, baik data barang, maupun pemasok.

\subsection{Ruang Lingkup}

Mengingat permasalahan yang ada di Unit Logistik Bank Indonesia Bandung cukup luas, maka ruang lingkup penelitian ini dititikberatkan pada aktivitas permintaan atau pengajuan barang persediaan ke Unit Logistik. Adapun ruang lingkup penelitian ini diantaranya adalah sebagai berikut :

a. Pengelolaan data barang, pemasok.

b. Transaksi permintaan atau pengajuan barang ke Unit Logistik.

\section{Metodologi Penelitian}

Perancangan Sistem Aplikasi Inventori ini, dilakukan dengan beberapa tahapan, diantaranya yaitu, yaitu pengumpulan data, analisis sistem, perancangan proses, perancangan basis data, dan pengkodean.

Teknik yang dilakukan dalam tahap pengumpulan data adalah :

a. Interview (wawancara), yaitu dengan melakukan wawancara langsung dengan staf atau karyawan di Bank Indonesia Bandung.. b. Studi pustaka, yaitu dengan mempelajari buku-buku, referensireferensi yang ada sangkut pautnya dengan pembuatan laporan ini.

c. Studi observasi, peninjauan secara langsung ke kantor Bank Indonesia Bandung.

III. Analisis, Perancangan dan

\section{Pembahasan}

Menurut Sven Axsater (2015) Inventory adalah bahan yang digunakan dalam produksi yang mengalir melalui suatu process pengadaan barang mulai dari barang keluar sebagai bahan baku atau barang yang merupakan bagian yang dibeli serta perubahan bentuk barang dalam produksi menjadi bentuk suatu produk.

Optimalisasi Inventori dilakukan dengan menggunakan konsep just in time yaitu : dengan menghitung minimal stock inventori disesuaikan dengan jadwal permintaan barang, sehingga bagian pengadaan barang menyediakan kebutuhan barang tepat waktu sesuai dengan jadwal permintaan dengan demikian penumpukan stock inventori digudang bisa diminimalisir.

\subsection{Analisis}

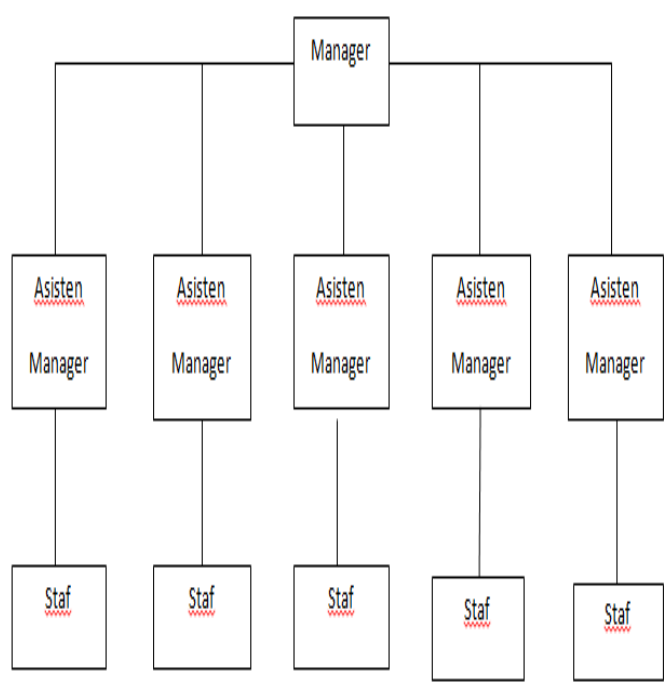

Gambar 1. Struktur Organisasi Unit Logistik Kantor Bank Indonesia Bandung

Bagian-bagian yang terlibat dalam Unit Logistik Kantor Bank Indonesia Bandung, diantaranya adalah :

a. Manager berperan sebagai Kepala Unit Logistik. Tugas pokoknya antara lain : 
1. Mengkoordinasikan penyusunan dan evaluasi realisasi program kerja KBI

2. Melaksanakan dan menatausahakan pengadaan barang dan jasa

3. Melaksanakan penghapusan barangbarang inventaris dan kendaraan

4. Melaksanakan pemeliharaan gedung, inventaris kantor, rumah dinas, rumah istirahat, dan perabotnya serta sarana lainnya.

5. Menyelesaikan tagihan listrik, air, telepon, dan gas serta jasa oihak ketiga lainnya.

6. Membuat laporan berkala yang berkaitan dengan logistik.

b. Asisten Manager berperan sebagai Pelaksana di Unit Logistik. Tugas pokoknya antara lain :

1. Membantu penyusunan dan evaluasi atas realisasi program kerja dan anggaraan.

2. Menata usahakan dan melaksanakan pengadaan barang dan jasa

3. Melaksanakan pemeliharaan gedung, inventaris kantor, rumah dinas, rumah istirahat, dan perabotnya serta sarana lainnya

4. Menyelesaikan tagihan listrik, air, telepon, dan gas serta jasa oihak ketiga lainnya

5. Membuat laporan berkala yang berkaitan dengan logistik.

c. Staf berperan sebagai Pelaksana Yunior.Tugas pokoknya antara lain :

1. Membantu pelaksanaan kegiatan terkait pengelolaan dokumen.

2. Membantu menyelenggarakan administrasi dalam rangka pelaksanaan tugas unit kerja, yang meliputi : Penyusunan laporan, suratsurat, dan dokumen lainnya, pengelolaan data anggaran dan atau data lainnya, Pengadministrasian arsip-arsip terkait dengan bidang tugas.

3. Membantu kelancaran dalam pengelolaan anggran di lingkup unit kerja

4. Membantu kelancaran pelaksanaan tugas-tugas di lingkup unit kerjanya.

\subsubsection{Analisis Prosedur}

Prosedur permintaan atau pengajuan barang ke Unit Logistik diantaranya adalah:

1. Permintaan atau pengajuan barang persediaan ke Unit Logstik, dilakukan sebanyak satu kali dalam satu minggu.

2. Jumlah barang yang diminta tidak dibatasi, namun apabila stok barang yang diminta tidak mencukupi, maka Unit Logistik, hanya akan mengeluarkan barang seadanya saja

\subsubsection{Analisis Sistem Yang Berjalan.}

Pengolahan data inventory, khususnya untuk aktivitas permintaan barang persediaan, masih belum optimal, karena masih menggunakan cara manual, belum menggunakan sistem terkomputerisasi, sehingga dapat menghambat kinerja aktivitas permintaan barang, yang seharusnya dikerjakan efektif dan efisien.

Adapun permasalahan yang ada pada saat ini, diantaranya adalah :

a. Aktivitas permintaan atau pengajuan barang persediaan, masih menggunakan cara manual.

b. Pengelolaan data inventori masih belum optimal, sehingga cukup memakan waktu lama.

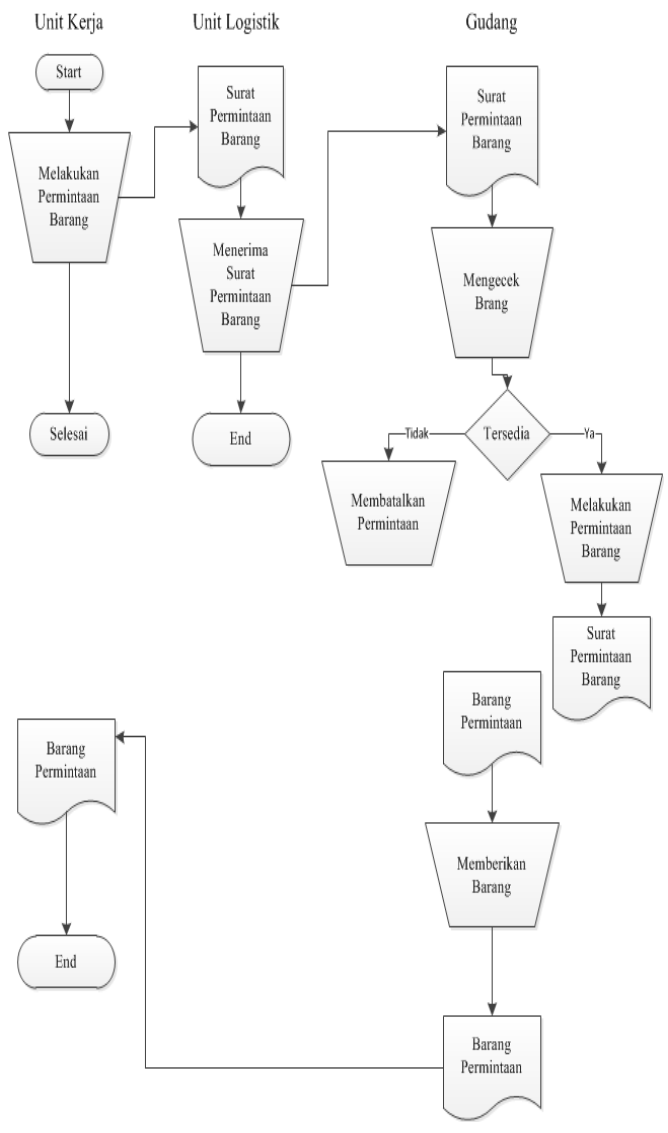

Gambar 2. Flow Diagram Sistem Yang Berjalan.

Berdasarkan Gambar 2 diatas terdapat permasalahan dari aktivitas permintaan barang persediaan ini, diantaranya adalah:

a. Belum terdapatnya sistem informasi permintaan barang persediaan di Unit Logistik Kantor Bank Indonesia Bandung.

b. Pencarian data inventori, masih menggunakan sistem manual, sehingga tidak efektif dan efisien. 


\subsubsection{Hasil Analisis}

Berdasarkan identifikasi penyebab masalah yang telah dijelaskan dapat disimpulkan bahwa untuk memperbaiki aktivitas di Unit Logistik tersebut, maka diperlukan :

a. Sebuah database yang dapat menampung seluruh data inventori.

b. Sebuah sistem yang dapat mengolah database secara optimal, serta mudah dalam pemakaiannya.

c. Sebuah sistem yang dapat mengolah aktivitas inventory, khususnya untuk kegiatan permintaan barang persediaan.

\subsection{Hasil Perancangan}

Menurut Kurt Bittner dan lan Spence dalam bukunya yang berjudul Use Case Modelling (2002), aktor adalah segala hal diluar sistem yang akan menggunakan sistem tersebut, tetapi tidak semua aktor adalah manusia, bisa saja sistem lain yang berinteraksi dengan sistem yang dibuat.

Dengan menggunakan Use Case Modelling ini, maka pengolahan data inventory dan transaksi utama menjadi lebih mudah dan akurat selain itu pencarian data pun menjadi lebih cepat dan optimal.

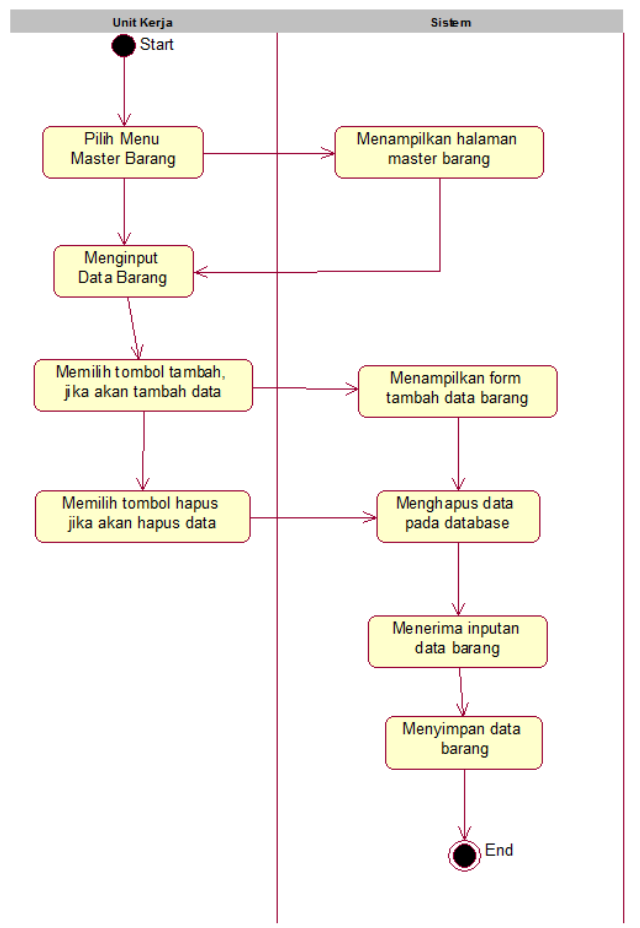

Gambar 3. Activity Diagram Input Data Barang

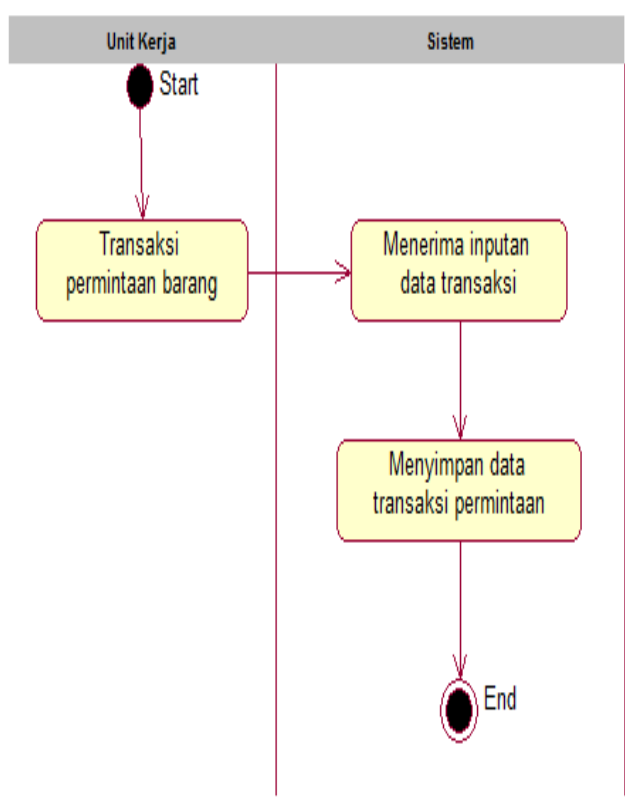

Gambar 4. Activity Diagram

Menerima dan Menyimpan

Transaksi Permintaan Barang.

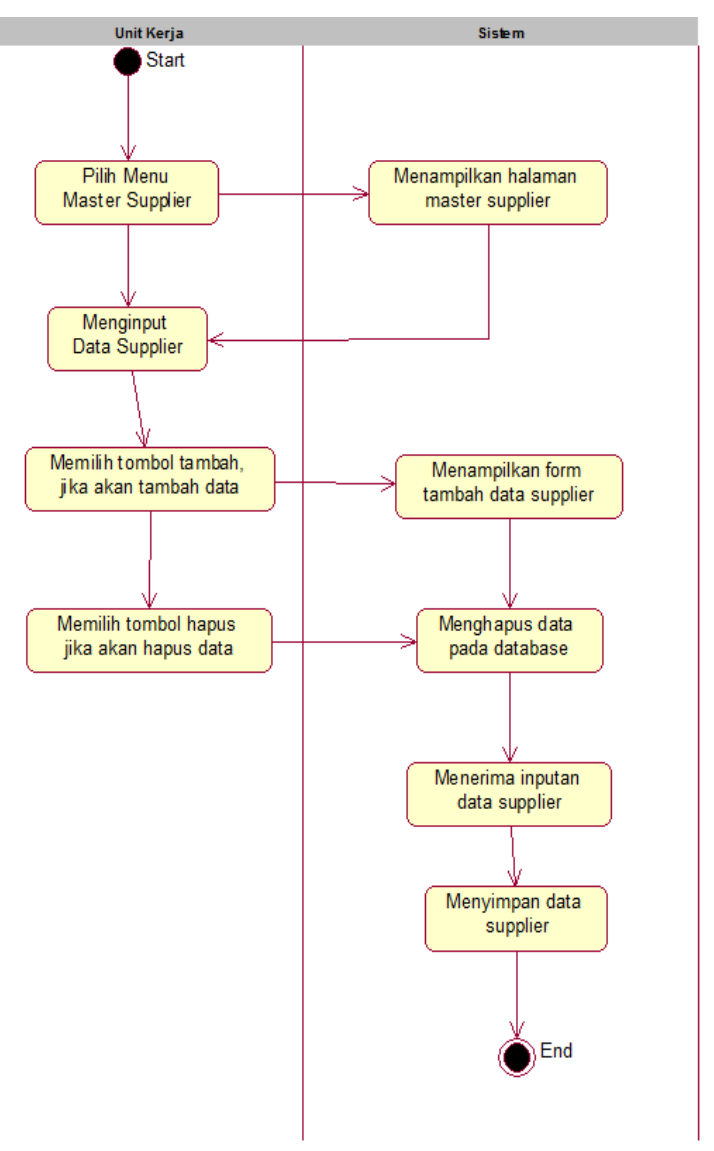

Gambar 5.Activity Diagram Input Data Supplier 


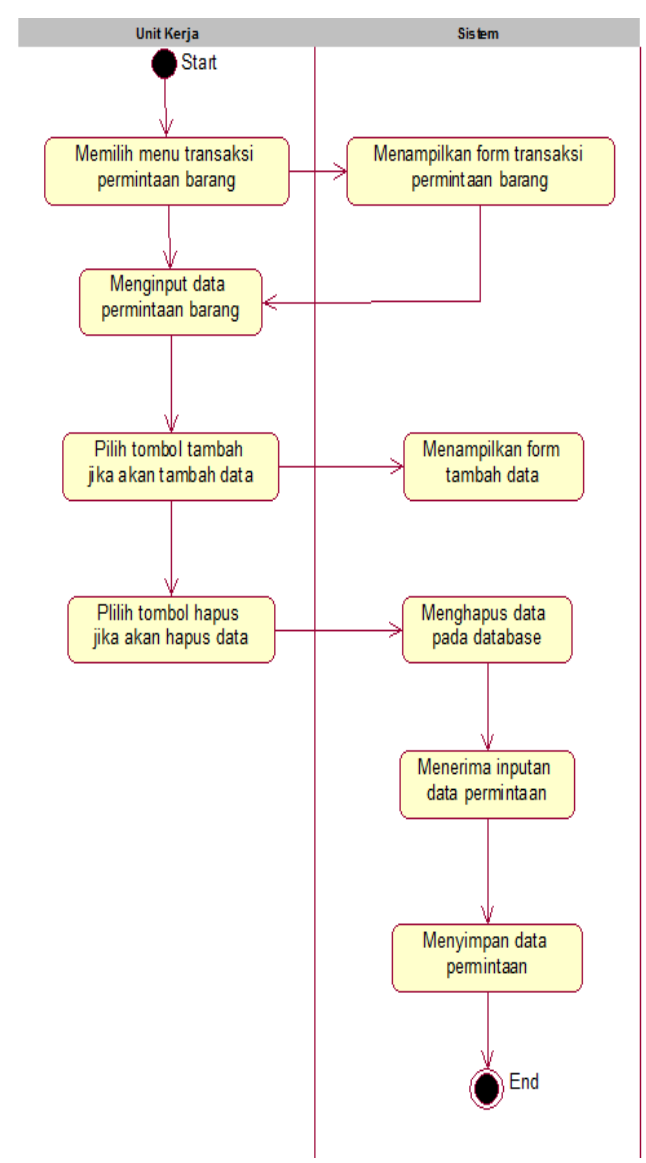

Gambar 6. Activity Diagram Transaksi Permintaan Barang

\subsection{Pembahasan}

\subsubsection{Tampilan Menu Master}

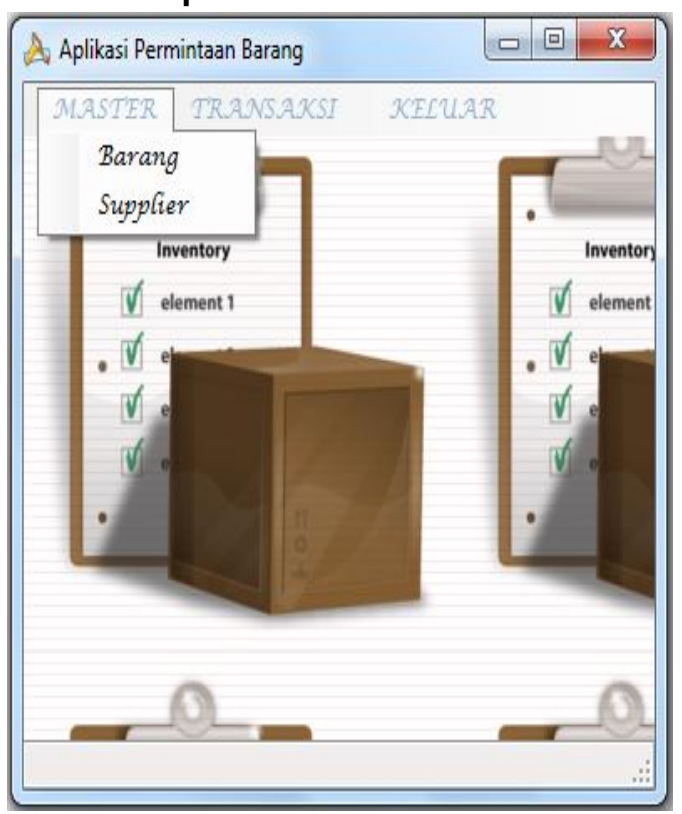

Gambar 7. Menu Master

Dimenu master terdiri dari dua sub menu, yaitu barang dan supplier. Menu ini berfungsi untuk menampilkan informasi berupa data inventaris dan data pemasok.

\subsubsection{Tampilan Menu Transaksi}

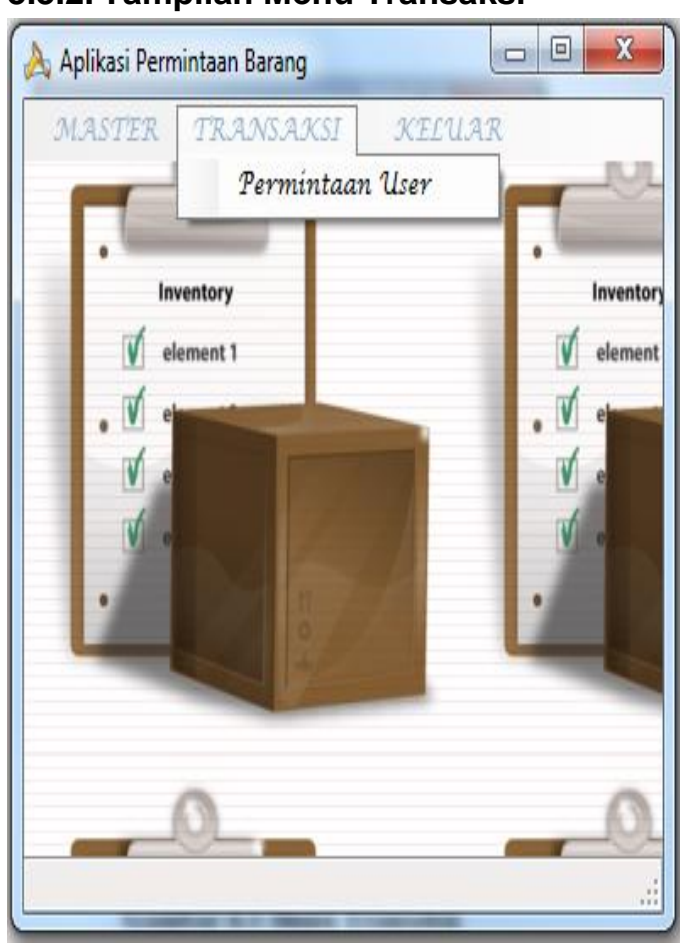

Gambar 8. Menu Transaksi

Menu transaksi hanya terdiri dari satu sub menu, yaitu transaksi permintaan user, yang berfungsi untuk menampilkan informasi untuk melakukan permintaan barang.

\subsubsection{Tampilan Menu Master Barang}

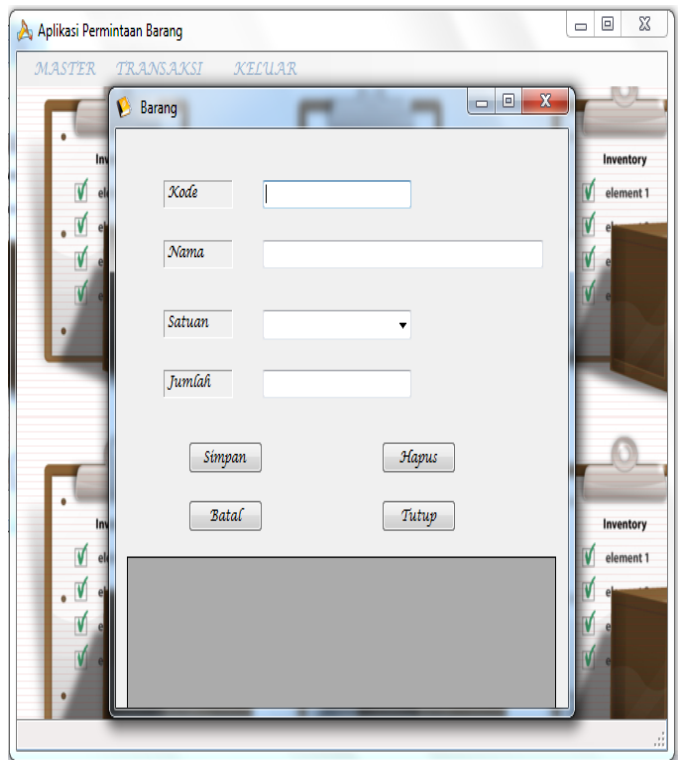

Gambar 9. Menu Master Barang

User harus menginputkan kode, nama, satuan, dan jumlah barang yang diminta. 
Kemudian user dapat memilih simpan untuk menyimpan data yang telah diinputkan, pilih hapus untuk memperbaharui data barang, caranya adalah dengan menginputkan kode barang terlebih dahulu. Kemudian pilih batal bila user tidak akan menginputkan data di master barang, dan pilih tutup untuk keluar dari antar muka ini. Data yang sudah diinputkan dengan lengkap, akan muncul dikolom di master data barang.

\subsubsection{Tampilan Menu Master Supplier}

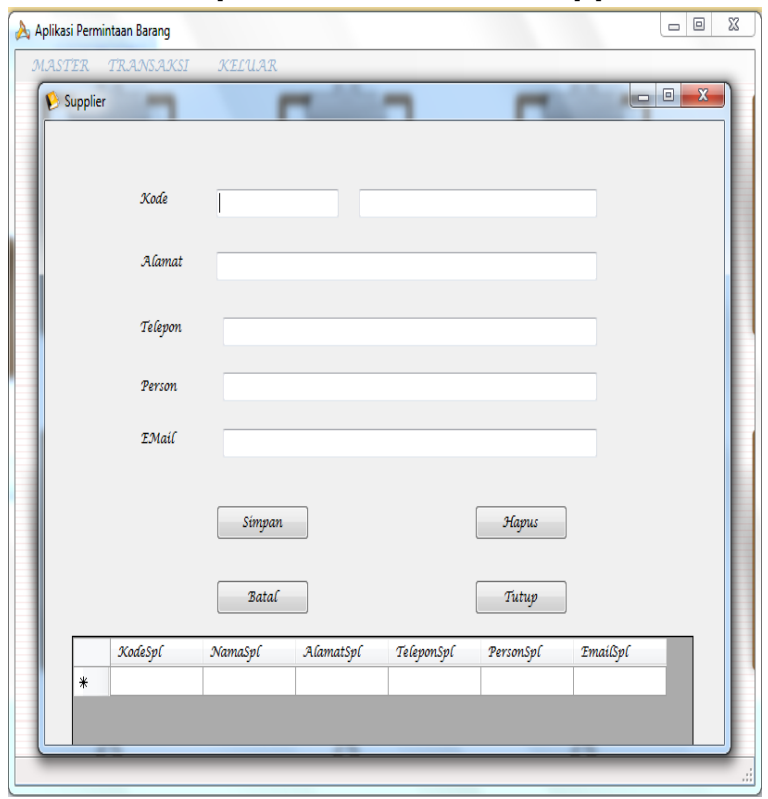

Gambar 10 Menu Master Supplier

Pada gambar 10 diatas merupakan tampilan antar muka data pemasok. User harus menginputkan kode, nama, alamat, telepon, contact person, dan email pemasok. Kemudian user dapat memilih simpan untuk menyimpan data yang telah diinputkan, pilih hapus untuk memperbaharui data pemasok , caranya adalah dengan menginputkan kode pemasok terlebih dahulu. Kemudian pilih batal bila user tidak akan menginputkan data di master supplier, dan pilih tutup untuk keluar dari antar muka ini. Data yang sudah diinputkan dengan lengkap, akan muncul dikolom di master data supplier.

\subsubsection{Tampilan Menu Transaksi Permintaan Barang}

Gambar 11 dibawah menunjukkan transaksi permintaan barang, user harus memasukan semua data yang diminta pada form tersebut, yaitu dengan cara memilih kode customer yang secara otomatis sudah tersimpan di database, customer yang dimaksud disini adalah unit kerja yang akan mengajukan permintaan barang, bisa diasumsikan mereka adalah customernya.

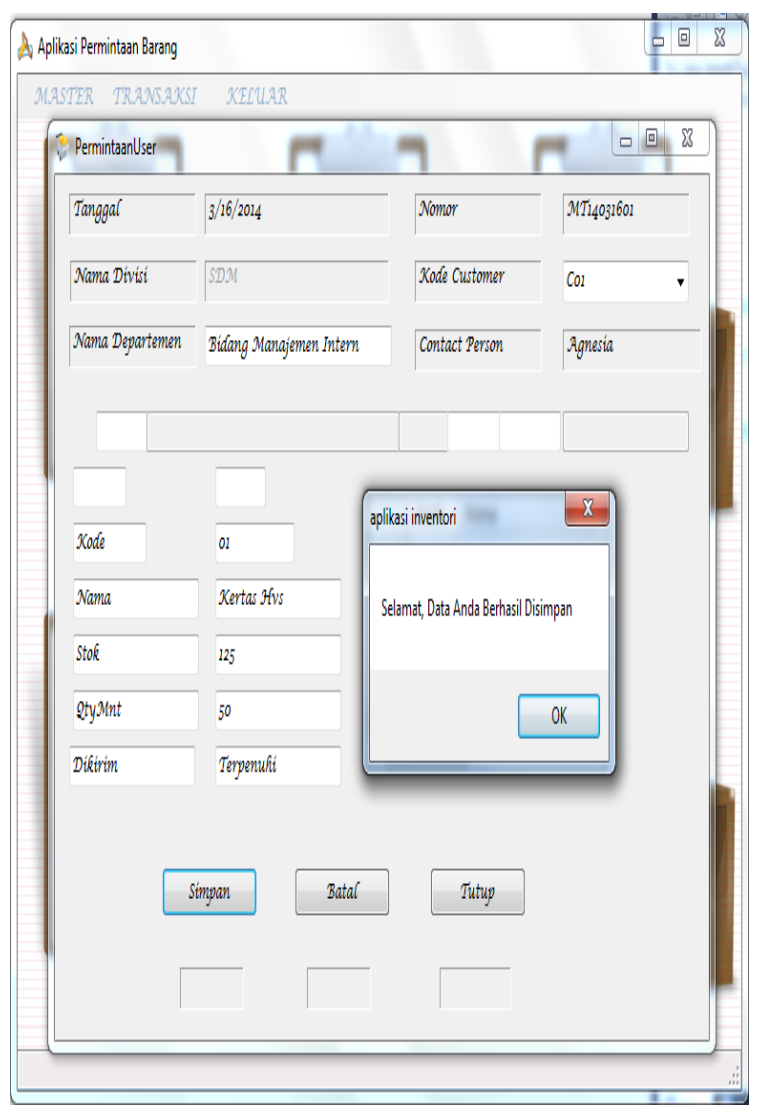

Gambar 11. Transaksi Permintaan Barang Berhasil Disimpan

Pada gambar diatas, misalnya C01 merupakan kode customer untuk Agnesia. C merupakan Customerdan 01 merupakan id untuk Agnesia sebagai user.Untuk tanggal dan nomor akan muncul secara otomatis dengan format bulan, tanggal, dan tahun. Sedangkan untuk nomor MT yang berarti minta, karena aplikasi ini meminta barang kepada Unit Logistik. Setelah kode MT diikuti dengan 16091601, yang artinya merupakan waktu yang menunjukkan user mengajukan permintaan barang, yaitu tahun 2016 bulan ke9 yaitu September, dan tanggal 16 .

Kemudian nama divisi sudah tersimpan pula secara otomatis di database sehingga user hanya memilih nama departemennya saja. Untuk nama departemen, user harus menginputkannya.

Untuk melakukan permintaan barang, user memasukan informasi yang ada diform permintaan user, diantaranya kode, nama, stok yang tersedia di gudang, kuantitas atau jumlah 
barang yang diminta, dan informasi barang untuk dikirim.

\section{IV.Penutup}

\subsection{Kesimpulan}

1.Aplikasi ini mempermudah para pegawai melakukan pencarian data barang dan supplier dalam melakukan transaksi permintaan barang, sehingga dengan menggunakan aplikasi ini pengelolaan inventori menjadi lebih optimal terbukti dari aktifitas perencanaan, pengadaan, pengawasan, pemeliharaan, penataan, pemanfaatan dan penghapusan barang kegiatannya berjalan dengan sangat baik.

2.Sistem ini dapat dijalankan atau dioperasikan dengan baik dan mudah oleh user sesuai dengan semua inputan data pada database yang telah disusun.

3. Aplikasi yang dirancang diharapkan dapat memberikan hasil data transaksi yang akurat dan dapat menghindari redudancy.

\subsection{Saran}

1.Perlu adanya peningkatan dalam sistem keamanan data.

2. Perlu dilakukan pengujian untuk mencari berbagai kekurangan-kekurangan pada perangkat lunak sehingga bisa dilakukan perbaikan-perbaikan sesuai dengan kekurangan yang didapatkan.

3. Aplikasi ini perlu dikembangkan dan diperbaiki seiring berkembangnya kebutuhan perusahaan.

\section{V.DAFTAR PUSTAKA}

Bittner Kurt \& Ian Spence (2002). "Use Case Modelling" ,Booch Jacobson Rumbaugh.

Dennis, Wixom, and Tegarden (2015). "Systems Analysis and Design: An ObjectOriented Approach with UML, $5^{\text {th }}$ Edition" Willey.

Harry J. Rossenblatt (2013). "System Analysis \& Design", Shelly Cashman Series.

Sven Axsäter (2015). “ Inventory Control (International Series Operations Research \& Management Science) ", Springer. 